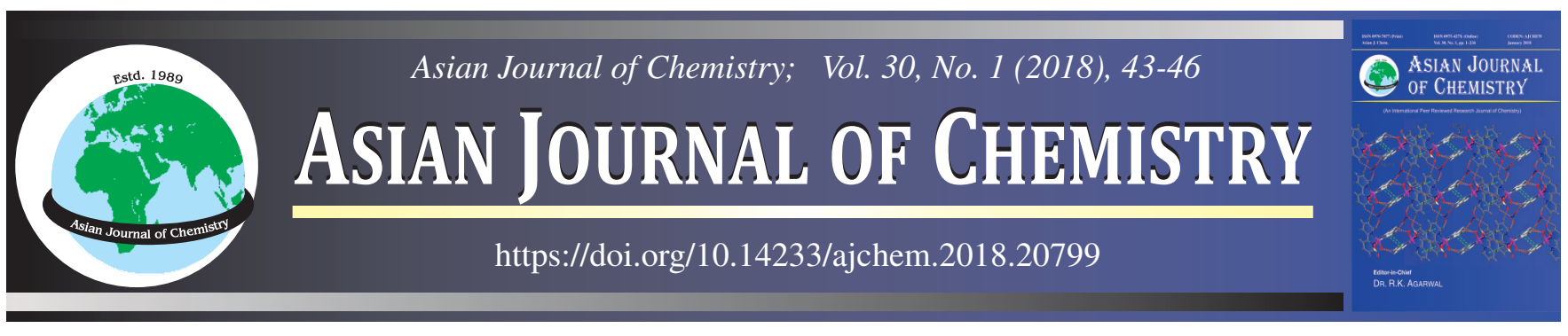

\title{
Cellulose Micro/Nanofibres of Merbau (Intsia bijuga) Waste: Effects of Chemical Treatments on Structural and Morphology Features
}

\author{
Nur Amira Mamat Razali ${ }^{1, *}$, Fauziah Abdul Aziz ${ }^{1}$ and Saadah Abdul Rahman ${ }^{2}$
}

${ }^{1}$ Department of Physics, Centre for Defence Foundation Studies, Universiti Pertahanan Nasional Malaysia, Kem Sg. Besi, 57000, Kuala Lumpur, Malaysia

${ }^{2}$ Department of Physics, Faculty of Science, University of Malaya, 50603 Kuala Lumpur, Malaysia

*Corresponding author: Tel: +60 1 111185525; E-mail: 3080355@alfateh.upnm.edu.my; nuramira.mamatrazali@gmail.com

\section{INTRODUCTION}

Cellulose and lignocellulose have great potential in the production of nanomaterials because they are abundant, renewable, have nanofibril structure and can be made multifunctional and self-assemble into distinct architectures [1-5]. As early as 1838, the term "cellulose" was first used by the French chemist Anselme Payen, when he revealed that after refinement of various plant tissues with an acid-ammonia treatment, then followed by an extraction in water, alcohol and ether, a constant fibrous material remains. He determined the molecular formula to be $\left(\mathrm{C}_{6} \mathrm{H}_{10} \mathrm{O}_{5}\right)_{\mathrm{n}}$ and observed the isomerism of its structure with starch. Since then, it has been generally accepted that cellulose is a linear polymer consisting of anhydroglucose units joined together by $\beta$-1,4-glycosidic linkages [6]. Cellulose from plant cell walls is the world's most abundant renewable resource. In the cell wall structures of vegetable plants, these cellulose nanocrystals is joined together by amorphous holocellulose parts to form cellulose micro/ nanofibres (CMNF) that found the individual cellulose fibers [7]. There is approximately 1.5 trillion tonnes of cellulose grown annually worldwide. Lignocellulose (wood) from tree is $38-50 \%$ cellulose, $23-32 \%$ hemicellulose and $15-25 \%$ lignin $[8,9]$. The use of lignocellulosic fibres derived from sustainable, annually renewable resources as a reinforcing phase in polymeric matrix composites, provides constructive environmental benefits with respect to biodegradability and the energetic cost of production. Research has shown that by adding an ounce of crystal (of cellulose) to a pound of plastic, the strength of the plastic can be increased by factor of 3000 [10].

Isolation of cellulose fibrils including nano-cellulose from plant cell wall has gained considerable research attention [11-13]. It is difficult to produce purely single solid crystal due to its polymorphic behaviour. Another obstacle is increase of defibrillation of cellulose molecule and rearrangement of hydrogen bonds during isolation. Cellulose micro/nanofibre is normally produced in polymorphic form. The presence of various phases is source dependent [14-16]. Chemical treatments on cellulose micro/nanofibres seem to be one of the ways of better exploiting the potential of cellulosic fibres compared to the usual paper-based application. Depending on the fibrous raw materials, pre-treatment and fibrillation condition, different types of micro or nanofibres cellulose can be obtained in terms of microfibrilles individualization, dimensions, crystallinity and crystallite size. Moreover, the chemical treatment of micro or nanofibres' surfaces not only can impart different functionalities but can also be used as pre-treatment for their production. The most studied source materials for the obtaining of cellulose micro/nanofibres are wood, bacterial cellulose, agricultural residues, leaf fibre, the shell of some fruits and vegetables [17].

This study has focused on a species of Malaysian wood, the Merbau (Intsia bijuga) from Pahang. The timber of Merbau (Intsia bijuga) species is known to be durable under exposed 
conditions. It is suitable for a wide range of purposes because of its favourable physical and mechanical properties. Merbau is used in house-building, especially for high-class exterior joinery such as for window and weather boarding. It is also used for furniture-making and waterworks construction. The work described here aims to characterize cellulose micro/ nanofibres from Merbau (Intsia bijuga) using X-ray diffraction (XRD) and field emission scanning electron microscope (FESEM) and to investigate the effects of chemical treatment on its structural and morphology features.

\section{EXPERIMENTAL}

Hardwood Merbau (Intsia bijuga) as the wood samples were supplied by the Forest Research Institute Malaysia (FRIM) Kepong, Malaysia. The samples were cut into small pieces ( $1 \mathrm{~cm}$ length) and were ground using Thomas Miller grinder. The samples of Merbau (Intsia bijuga) were screened to a nominal size of $250 \mu \mathrm{m}$ into powder form. After that the wood powder was washed twice with distilled water to remove the wax and sand particles. Finally the wood powder was dried in an oven at a temperature of $50-70{ }^{\circ} \mathrm{C}$ until only $5 \%$ of moisture content of the wood sample remained. The dried sample was ready for delignification process. The colour of the samples was dark brown when they were obtained but their colour changed after the extraction process.

Four kinds of extraction process were performed in this research e.g., delignification, acid bleach, alkaline bleach and alkaline treatment process. The solid to liquid ratio of all extraction was 10:1. This ratio was based on the dry weight of solid fibres over the weight of liquid (w/w). Dried Merbau (Intsia bijuga) samples were delignified (1:10 solid to liquid ratio) at $70-80{ }^{\circ} \mathrm{C}$ for $5 \mathrm{~h}$ in acetic acid or hydrogen peroxide media $\left(\mathrm{CH}_{3} \mathrm{COOH} / \mathrm{H}_{2} \mathrm{O}_{2}\right)$ with the addition of $5 \%$ sulphuric acid. In the first stage, the delignified cellulose was doublebleached in $4 \% \mathrm{H}_{2} \mathrm{O}_{2}$ and $\mathrm{CH}_{3} \mathrm{COOH}$ until the mixture reached $\mathrm{pH} 3.5$ at $60-70{ }^{\circ} \mathrm{C}$ for $45 \mathrm{~min}$. These samples were then tagged as acid bleach. The second stage was the alkali bleach. The delignified cellulose was bleached in $0.02 \mathrm{M}$ sodium hydroxide containing $4 \% \mathrm{H}_{2} \mathrm{O}_{2}$ at $60-70{ }^{\circ} \mathrm{C}$ for $45 \mathrm{~min}$. The last stage is known as alkaline treatment. In this stage, the alkaline bleached cellulose was treated with $17.5 \% \mathrm{NaOH}$ solution at room temperature $\left(27^{\circ} \mathrm{C}\right)$ for $15 \mathrm{~min}$. All samples were tagged as indicated in Table-1.

X-ray diffraction: X-ray diffraction patterns were acquired from Siemens D5000 using $\mathrm{CuK}_{\alpha}$ radiation with a wave length equals to $0.15406 \mathrm{~nm}$ with $2 \theta$ angle ranging from $5^{\circ}$ to $80^{\circ}$. The scanning speed started at $0.05^{\circ}$ per $5 \mathrm{~s}$. The crystallinity index was calculated manually using the Segal method [18]. According to this method, crystallinity $\left(\mathrm{X}_{\mathrm{c}}\right)$ is expressed as shown in eqn. 1 :

$$
X_{c}=\frac{\left(I_{002}-I_{a m}\right)}{I_{002}}
$$

where $\mathrm{I}_{002}$ is the maximum intensity of diffraction of the (002) lattice peak at a $2 \theta$ angle between $22^{\circ}$ and $23^{\circ}$ and $I_{a m}$ is the diffraction intensity of the amorphous material, which was taken at $2 \theta$ angle between $15^{\circ}$ to $19^{\circ}$ where intensity was at the minimum level [19].

$$
\mathrm{D}_{002}=\frac{\mathrm{k} \lambda}{\mathrm{B}_{002} \cos \theta}
$$

The average crystallite size was calculated using Scherrer formula (eqn. 2) according to the diffraction pattern at 002 lattice plane, where $D_{\text {hkl }}$ is the crystallite dimension in the direction perpendicular to the crystallographic plane hkl, $\theta$ is the Bragg angle, $\lambda$ is the wavelength of the radiation, $\mathrm{k}$ is the Scherrer constant 0.84 [20] while B refers to the full width high maximum (FWHM).

Field emission scanning electron microscope (FESEM): The morphology of samples in this research was investigated using JEOL JSM-7600F FESEM. The samples were mounted on a specimen stub with copper tape on the sample preparation workbench. The specimen stub was then fixed onto a specimen holder. The specimen stub was then locked with screws. The distance from the surface of the specimen holder to the specimen surface was measured. After setting up the samples, they were loaded in the system analysis chamber where the samples' images were recorded.

\section{RESULTS AND DISCUSSION}

Characterization of cellulose with XRD technique was made by analyzing the diffraction pattern. Crystallinity and crystallite size obtained from powder X-ray diffraction data were calculated according to the Segal method. This method is fast and simple. It uses the height of $(002)$ peak $\left(\mathrm{I}_{002}\right)$ and the minimum between (002) and (110) peaks denoted as $I_{a m}$, assuming that intensity of (002) represents both crystalline and amorphous parts while the minimum intensity at the mentioned location is for amorphous only [21].

Morphology: FESEM image of untreated material (RAW), post delignification cellulose (PDC), acid-bleached cellulose (ACBC), alkali-bleached cellulose (ALBC) and alkali-treated cellulose (ATC) were obtained from Merbau (Intsia bijuga) waste fibres. The average diameter of sample was in the range of 12.22 to $25.67 \mu \mathrm{m}$ (Table-2). This diameter value was higher than other samples (PDC, ACBC, ALBC and ATC).

Fig. 1 shows the typical images of cellulose product samples after chemical treatment. The colour of cellulose powder sample of post delignification process was sticky yellow and the diameter of the sample (Fig. 2 PDC) was in range of 4.44 to $15.56 \mu \mathrm{m}$ (Table-2). This stage has reduced the thickness of the fibre but it did not change the surface of the fibre. Then, the fibres were bleached using acidic media. From the observation, the morphology of the fibres has changed (Fig. 2 ACBC). The colour of the sample was light yellow (Fig. 1 ACBC). Acid bleached treatment has changed the diameter of the fibres

\begin{tabular}{cccccc}
\multicolumn{1}{c}{ TABLE-1 } \\
\hline LABELS OF SAMPLES IN THIS RESEARCH \\
\hline Sample & $\begin{array}{c}\text { Untreated } \\
\text { material }\end{array}$ & $\begin{array}{c}\text { Post delignification } \\
\text { cellulose }\end{array}$ & $\begin{array}{c}\text { Acid-bleached } \\
\text { cellulose }\end{array}$ & $\begin{array}{c}\text { Alkali-bleached } \\
\text { cellulose }\end{array}$ & $\begin{array}{c}\text { Alkali-treated } \\
\text { cellulose }\end{array}$ \\
\hline Merbau (Intsia bijuga) & RAW & PDC & ALBC & ACBC & ATC \\
\hline
\end{tabular}



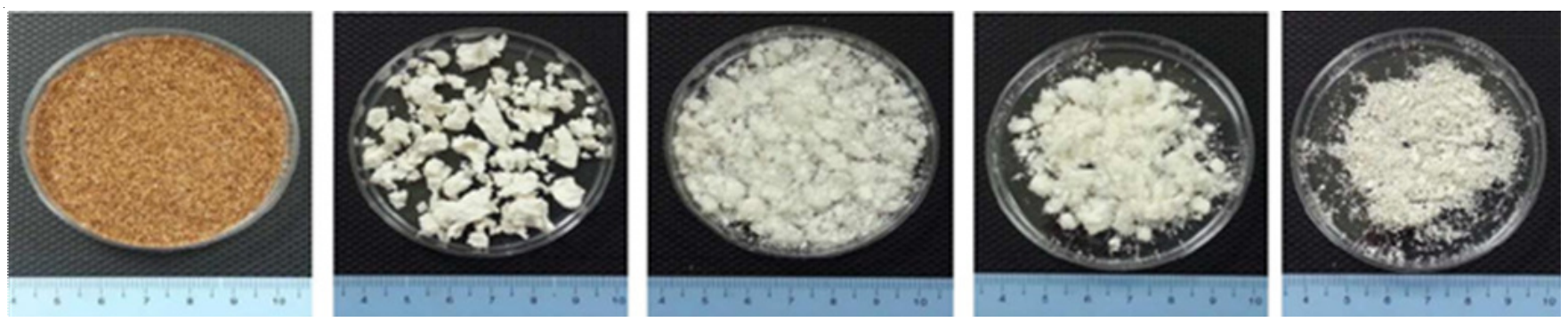

Fig. 1. Images of products (RAW, PDC, ACBC, ALBC and ATC)
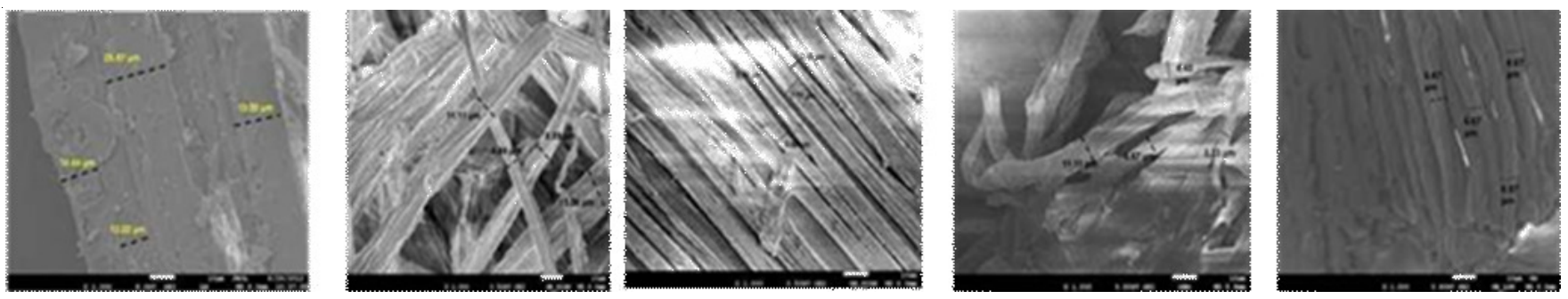

Fig. 2. Micrographic FESEM images of RAW, PDC, ACBC, ALBC and ATC

TABLE-2

RANGE OF MICROFIBRIL DIAMETER OF CELLULOSE SAMPLES USED FROM MERBAU (Intsia bijuga)

\begin{tabular}{lcc}
\hline \multicolumn{1}{c}{ Samples } & $\begin{array}{c}\text { Microfibril } \\
\text { diameter } \\
(\mu \mathrm{m})\end{array}$ & $\begin{array}{c}\text { Average } \\
\text { microfibril } \\
\text { diameter }\end{array}$ \\
\hline Untreated material (Merbau, Intsia & $12.22-25.67$ & 16.415 \\
bijuga) (RAW) & $4.44-15.56$ & 10.000 \\
Post delignification cellulose (PDC) & $3.33-7.78$ & 5.555 \\
Acid-bleached cellulose (ACBC) & $3.33-11.11$ & 6.390 \\
Acid-bleached cellulose (ACBC) & 6.67 & 6.670 \\
Alkali-treated cellulose (ATC) & & \\
\hline
\end{tabular}

making it smaller $(5.839 \mu \mathrm{m})$ and the surface of the fibres became smoother i.e. by removing the fibrillars. However, as the fibres were bleached in alkali as shown in Fig. 2 (ALBC), the surface of the fibres became much smoother compared to post delignification cellulose but the diameter became bigger $(6.390 \mu \mathrm{m})$ than the acid-bleached cellulose $(5.839 \mu \mathrm{m})$ although the colour of both samples were similar (Fig. 1 ALBC), (Fig. 1 ACBC) to acid-bleached cellulose powder. Fig. 2 (ATC) shows the morphology of the alkali-treated cellulose. The colour of the sample was whitish. The morphology clearly showed the change in the arrangement of the fibre chain. The arrangement was more ordered and the diameter of the fibres was the same compared to others but the diameter and surface fibres were smaller than the acid-bleached cellulose $(5.839 \mu \mathrm{m})$.

Therefore, it clearly showed that the acid-bleached cellulose has great surface character compared to other cellulose fibres. It is small in diameter $(5.839 \mu \mathrm{m})$ and has smooth surface fibres. It also has the ordered fibres chain arrangement. The ordered arrangement of cellulose chain was shown in the morphology pattern in Fig. 2 ACBC. The micrographic FESEM of acidbleached cellulose showed the parallel chain structure. Therefore, this cellulose sample was classified as monoclinic structure, cellulose $\mathrm{I}_{\beta}$.

Fig. 2 shows the comparison of micrographic FESEM of RAW, PDC, ACBC, ALBC and ATC cellulose samples. Fig. 2, it shows that the average diameter of untreated raw material was the highest $(16.415 \mu \mathrm{m})$ compared to other cellulose samples. This is because it did not undergo any chemical treatment. After the chemical treatment, the diameter of cellulose samples became smaller. Cellulose samples that went through the process of acid bleaching (ACBC) showed the average lowest diameter $(5.555 \mu \mathrm{m})$ compared to samples that went through alkali bleaching (ALBC) and cellulose samples with strong alkali treatment (ATC). This is because acid is the best material to remove lignin and hemicellulose in wood.

Crystallinity and crystallite size: The results of crystallinities and crystallite size of the cellulose sample were tabulated in Table- 3 with their value of $2 \theta_{002}, d$-spacing (d) and full width half maximum (FWHM). The calculation of $X_{\mathrm{c}}$ and $\mathrm{D}_{\mathrm{hkl}}$ used the plane $h k l=002$ (Table-3). Crystallinity change has resulted from the use of different treatment medium. It can be seen from Table-2 that the crystallinity of cellulose samples increased from 3 to $19 \%$ after the chemical treatment. The percentages of crystallinity of cellulose samples were calculated based on the Segal method (eqn. 1). The crystallinity of cellulose material clearly depended on the type of cellulose samples and type of chemical treatments. This is due to the hydrogen bonding system of cellulose structure which has an important role during delignification process, purification and reaction of cellulose. Generally, the crystallinity increased from the untreated material (RAW) (57.2\%). Overall, acid-bleached cellulose has the highest crystallinity (82.4\%) compared to the other samples.

A combination of the X-ray diffraction diffractogram patterns obtained from this study is shown in Fig. 3. The untreated material (RAW), post delignification cellulose (PDC), acidbleached cellulose (ACBC) and alkali-bleached cellulose (ALBC) illustrated the pattern of X-ray diffraction of cellulose I [22]. Two peaks were located between $2 \theta=14^{\circ}$ and $16^{\circ}$ which are the position of (001) and (110) planes. While the third peak appeared at $2 \theta=23^{\circ}$. Whereas, for the alkali-treated cellulose (ATC), the diffractogram peaks were typical of cellulose II polymorph. These peaks were located at $2 \theta=12^{\circ}$, $19^{\circ}$ and $22^{\circ}$ which corresponded to the diffraction of (001), 


\begin{tabular}{|c|c|c|c|c|c|c|}
\hline \multicolumn{7}{|c|}{$\begin{array}{l}\text { TABLE-3 } \\
\text { THE } d \text {-SPACING, FULL WIDTH HALF MAXIMUM (FWHM), CRYSTALLINITY } \\
\text { INDICES }\left(\mathrm{X}_{002}\right) \text { AND CRYSTALLITE SIZES OF CELLULOSE SAMPLES }\end{array}$} \\
\hline $\begin{array}{c}\text { Samples } \\
\text { label }\end{array}$ & Sample & $2 \theta_{002}\left({ }^{\circ}\right)$ & $\mathrm{d}_{002}(\AA)$ & FWHM & $\begin{array}{l}\mathrm{D}_{002} \\
(\mathrm{~nm})\end{array}$ & $\mathrm{X}_{002}(\%)$ \\
\hline RAW & Untreated material (Merbau, Intsia bijuga) & 22.6127 & 3.93220 & 0.7872 & 9.6052 & 57.2 \\
\hline PDC & Post delignification cellulose $\left(35 \% \mathrm{H}_{2} \mathrm{O}_{2} / \mathrm{CH}_{3} \mathrm{COOH}, \sim 2.5 \% \mathrm{H}_{2} \mathrm{SO}_{4}\right)$ & 22.6500 & 3.92580 & 0.9229 & 8.1934 & 76.1 \\
\hline ACBC & Acid-bleached cellulose $\left(4 \% \mathrm{H}_{2} \mathrm{O}_{2} / \mathrm{CH}_{3} \mathrm{COOH}\right), \mathrm{pH} 3-4$ & 22.6368 & 3.92810 & 4.9200 & 1.5368 & 82.4 \\
\hline ALBC & Alkali-bleached cellulose $\left(0.02 \mathrm{M} \mathrm{NaOH} / 4 \% \mathrm{H}_{2} \mathrm{O}_{2}\right)$ & 22.6284 & 3.92953 & 3.6900 & 2.0491 & 78.8 \\
\hline ATC & Alkali-treated cellulose $(17.5 \% \mathrm{NaOH})$ & 21.8250 & 4.07230 & 2.0000 & 3.7755 & 77.9 \\
\hline
\end{tabular}

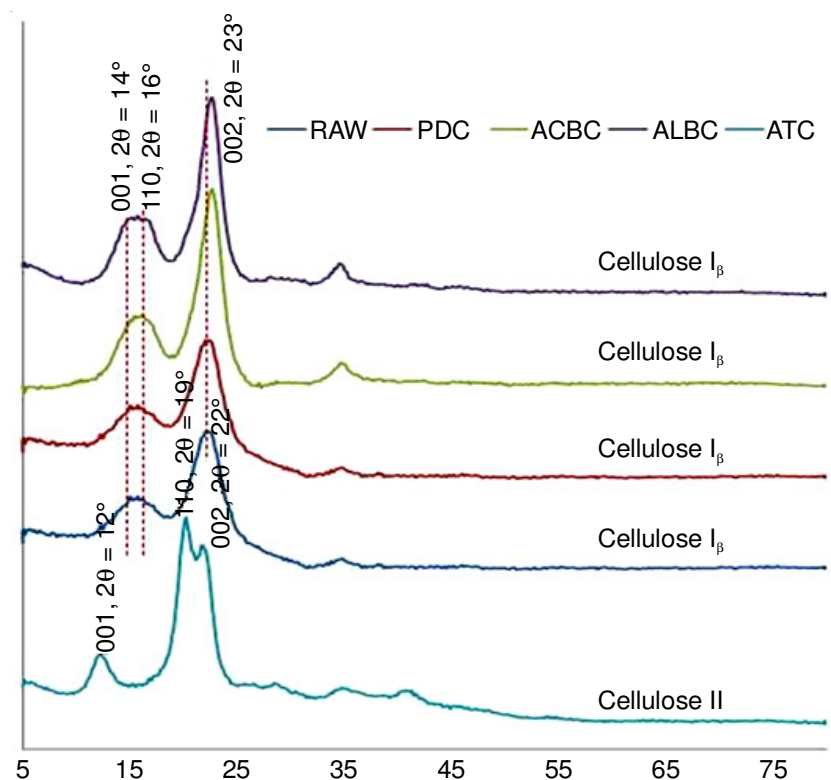

Fig. 3. Comparison of XRD patterns of cellulose samples of Merbau (Intsia bijuga)

(110) and (002) planes, respectively. This also showed the change of cellulose crystal type due to alkaline treatment in strong concentration of alkaline. For alkaline concentration of more than $10 \%$ has gradually changed the cellulose structure from cellulose I to cellulose II.

\section{Conclusion}

The extraction of cellulose from Merbau (Intsia bijuga) using various chemical treatments was conducted successfully. From the FESEM results, it showed that the average surface diameter size of untreated material (RAW), post delignification cellulose (PDC), acid-bleached cellulose (ACBC), alkalibleached cellulose (ALBC) and alkali-treated cellulose (ATC) are $16.405,10.000,5.839,6.390$ and $6.670 \mu \mathrm{m}$, respectively. Therefore, it was proven that the smallest size cellulose sample is obtained by using acid as the medium.

\section{ACKNOWLEDGEMENTS}

This work is done in collaboration with Forest Research Institute of Malaysia (FRIM), Universiti Pertahanan Nasional Malaysia (UPNM) and all members of the UPNM X-ray Research Group. The authors also wish to acknowledge the financial support by The Ministry of Higher Education under Niche Research Grant Scheme (NRGS) NRGS/2013/UPNM/PK/P1.

\section{REFERENCES}

1. S.D. Mohieldin, E.S. Zainudin, M.T. Paridah and Z.M. Ainun, Key Eng. Mater., 471-472, 251 (2011);

https://doi.org/10.4028/www.scientific.net/KEM.471-472.251.
2. N. Azraaie, N.A.M.Z. Abidin, N.A. Ibrahim, N.A.M. Razali, F.A. Aziz and S. Radiman, Adv. Mater. Res., 865, 174 (2014); https://doi.org/10.4028/www.scientific.net/AMR.895.174.

3. N.A.M.Z. Abidin, F.A. Aziz, R. Shahidan, N. Azraaie, N.A.M. Razali and N.A. Ibrahim, Adv. Mater. Res., 895, 134 (2014); https://doi.org/10.4028/www.scientific.net/AMR.895.134.

4. N.A. Ibrahim, N. Azraaie, N.A.M.Z. Abidin, N.A.M. Razali, F.A. Aziz and S. Zakaria, Adv. Mater. Res., 895, 147 (2014);

https://doi.org/10.4028/www.scientific.net/AMR.895.147.

5. C.W. Kim, D.S. Kim, S.Y. Kang, M. Marquez and Y.L. Joo, Polymer, 47, 5097 (2006);

https://doi.org/10.1016/j.polymer.2006.05.033.

6. N. Soykeabkaew, Ph.D. Thesis, All-Cellulose Composites, University of London, London (2007).

7. S.J. Eichhorn, A. Dufresne, M. Aranguren, N.E. Marcovich, J.R. Capadona, S.J. Rowan, C. Weder, W. Thielemans, M. Roman, S. Renneckar, W. Gindl, S. Veigel, J. Keckes, H. Yano, K. Abe, M. Nogi, A.N. Nakagaito, A. Mangalam, J. Simonsen, A.S. Benight, A. Bismarck, L.A. Berglund and T. Peijs, J. Mater. Sci., 45, 1 (2010); https://doi.org/10.1007/s10853-009-3874-0.

8. B. Deepa, E. Abraham, B.M. Cherian, A. Bismarck, J.J. Blaker, L.A. Pothan, A.L. Leao, S.F. de Souza and M. Kottaisamy, Bioresour. Technol., 102, 1988 (2011);

https://doi.org/10.1016/j.biortech.2010.09.030.

9. T.H. Wegner and P.E. Jones, Cellulose, 13, 115 (2006); https://doi.org/10.1007/s10570-006-9056-1.

10. M.T. Postek, A. Vladar, J. Dagata, N. Farkas, B. Ming, R. Sabo and J. Beecher, Proc. SPIE, 7042, pp. D-1-D-11 (2008); https://doi.org/10.1117/12.797575.

11. L. Brinchi, F. Cotana, E. Fortunati and J.M. Kenny, Carbohydr. Polym., 94, 154 (2013); https://doi.org/10.1016/j.carbpol.2013.01.033.

12. M. Cheng, W. Chen and T. Weerasooriya, J. Eng. Mater. Technol., 127, 197 (2005); https://doi.org/10.1115/1.1857937.

13. S.Y. Cho, Y. Choi, D. Park, S. Heo, D.H. Kim and H.J. Jin, Cellulose Nanocrystals with High Termal Stability and their nanocomposites with Poly (Lactic Acid), 18th International Conference on Composite Materials, Jeju Island, Korea (2011).

14. I. Siró and D. Plackett, Cellulose, 17, 459 (2010); https://doi.org/10.1007/s10570-010-9405-y.

15. S. Joseph, M.S. Sreekala, Z. Oommen, P. Koshy and S. Thomas, Compos. Sci. Technol., 62, 1857 (2002); https://doi.org/10.1016/S0266-3538(02)00098-2.

16. F.A. Aziz, A. Ismail, W.M.Z. Wan Yunus, N. Mohamad Nor, R.M. Sohaimi, A.Z. Sulaiman, N.A. Halim, D.D.I. Daruis, N. Azraaie, N.A.M. Zainul Abidin, N.A. Ibrahim and N.A.M. Razali, Mater. Sci. Forum, 846, 434 (2016);

https://doi.org/10.4028/www.scientific.net/MSF.846.434.

17. L. Donaldson, Wood Sci. Technol., 41, 443 (2007); https://doi.org/10.1007/s00226-006-0121-6.

18. L. Segal, J. Creely, A. Martin Jr. and C. Conrad, Text. Res. J., 29, 786 (1959); https://doi.org/10.1177/004051755902901003.

19. A.E. Oudiani, Y. Chaabouni, S. Msahli and F. Sakli, Carbohydr. Polym., 86, 1221 (2011); https://doi.org/10.1016/j.carbpol.2011.06.037.

20. M. Mohkami and M. Talaeipour, BioResources, 6, 1988 (2011).

21. Y. Wang, P.D. Thesis, Cellulose Fibre Dissolution in Sodium Hydroxide Solution at Low Temperature: Dissolution Kinetics and Solubility Improvement, Georgia Institute of Technology, Ann Arbor, USA (2008).

22. C.E. Crowder and T. Fawcett, Diffraction, Non-Crystallinity and the PDF Database from ICDD (2009). 